\title{
Assessment of the Validity of Self-Report as a Measure of Smoking Status in Patients Post-Myocardial Infarction
}

Sonia M. Grandi MSc, André Gervais MD, Lawrence Joseph PhD, Jennifer O'Loughlin PhD, Gilles Paradis MD MSc, Louise Pilote MD PhD, Stéphane Rinfret, MD MSc, Mark J. Eisenberg MD MPH

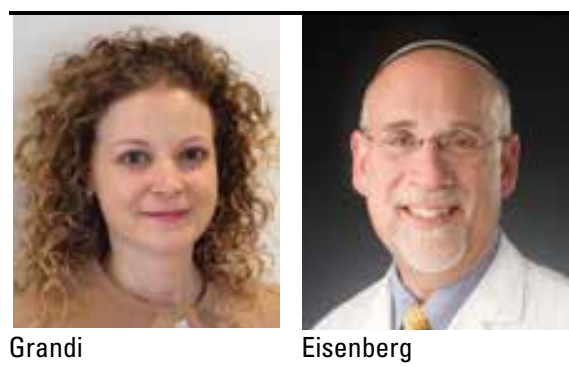

and Preventive Medicine and holds the Canadian Research Cha Paradis is professor and Chair of the Department of Epidemiology, Biostatistics, and Occupational Health at McGill University. He also holds a CIHR Chair in Applied Public Health Research. Stéphance Rinfret is a Junior 2 Physician-Scientist of the FRSQ. Correspondence may be directed to mark.eisenberg.mcgill.ca

\begin{abstract}
About the Authors
Sonia Grandi is a doctoral student at McGill University and is supported by the Frederick Banting and Charles Best Doctoral Award from the Canadian Institutes of Health Research (CIHR). Mark Eisenberg, Lawrence Joseph, and Louise Pilote are professors at McGill University in the Department of Epidemiology, Biostatistics, and Occupational Health and are Chercheurs Nationaux of the Fonds de la Recherche en Santé du Québec (FRSQ). Dr. Pilote holds a James McGill Chair at McGill University. Jennifer O'Loughlin is a professor at Université de Montréal in the Department of Social Canadian Research Chair in the Early Determinants of Adult Chronic Disease. Gilles
\end{abstract}

Summary

Self-report is the standard method for assessment of smoking status in the outpatient setting for myocardial infarction (MI) patients. However, the validity of self-report in this patient population has not been previously investigated. Using data from a double-blind, placebocontrolled, randomized trial we examined the validity of self-report for assessment of smoking status in an outpatient setting for MI patients. Smoking was assessed by self-report and biochemical validation by expired carbon monoxide $(\mathrm{CO})$. Abstinence was defined by a selfreport of no cigarettes smoked in the past week and a CO level of less than or equal to 10 parts per million (ppm). At 12 months, number of cigarettes smoked was positively correlated with CO level $(r=0.70)$. Results show that biochemical validation by CO does not substantially increase the likelihood of detecting smokers in MI patients. However, it may discourage patients from denying their smoking status and therefore should be considered for routine assessment of smoking status in the outpatient cardiac setting.

Current clinical guidelines for secondary prevention in myocardial infarction (MI) patients recommend routine assessment of smoking status. ${ }^{1}$ In clinical trials, biochemical validation in conjunction with self-report is the conventional method for assessment of smoking status. ${ }^{2-4}$ In the outpatient cardiac setting, self-report alone is used for routine assessment of smoking status.

\section{Résumé}

En consultation externe, l'on évalue habituellement le tabagisme selon les dires du patient, et il en va ainsi pour le patient ayant subi un infarctus du myocarde (IM). La validité de cette méthode (autoévaluation) dans ce groupe de patients n'a pas été étudiée. Nous reprenons les données d'un essai clinique randomisé, comparatif avec placébo et à double insu pour examiner la validité de l'autoévaluation dans la détermination du tabagisme en consultation externe chez des patients ayant subi un IM. Le tabagisme est évalué selon les dires du patient 
et par la validation biochimique au moyen d'un test respiratoire mesurant le monoxyde de carbone $(\mathrm{CO})$ expiré. L'abstinence s'entend du fait de ne pas avoir fumé de cigarettes dans la dernière semaine, selon ce qu'en dit le patient, et d'un taux de $\mathrm{CO} \leq 10$ parties par million (ppm). Au terme de 12 mois, il y a une corrélation positive entre le nombre de cigarettes fumées et le taux de $\mathrm{CO}(\mathrm{r}=0,70)$. Les résultats démontrent que la validation biochimique par la mesure du CO n'augmente pas vraiment la probabilité de détecter les fumeurs chez les patients ayant subi un IM. Cependant, cela peut décourager le patient de fausser la donne quant à son tabagisme; pour cette raison, l'on devrait envisager d'adopter cette méthode dans l'évaluation usuelle du tabagisme en clinique de soins cardiaques externes.

\section{Methods}

Data from a double-blind, placebo-controlled, randomized trial examining the efficacy of bupropion following an acute MI was used to evaluate the validity of self-report for assessment of smoking status. The full details of the study have been described elsewhere. ${ }^{10}$ Briefly, patients had to have smoked 10 or more cigarettes per day over the past year, be aged 18 years and over, and be motivated to quit smoking. A total of 392 patients hospitalized for an acute MI were randomized to receive bupropion or placebo for 9 weeks. Patients returned for clinic visits at 4 and 9 weeks and at 6 and 12 months. Both groups received motivational support at baseline and all follow-up visits. Motivational support consisted of a brief (two-minute) session with a physician prior to randomization followed by a session ( $\geq 5$ minutes) with a research nurse or smoking cessation counsellor (if available) at baseline (prior to discharge) and at all follow-up visits.

Smoking status was determined at each clinic visit by selfreport and biochemical validation by expired CO. Expired CO levels were measured using a Micro 4 Smokerlyzer monitor (Bedfont Scientific Ltd., USA) and are expressed in parts per million (ppm). In the original study, abstinence was defined by a self-report of no cigarettes smoked in the past week and an expired CO reading fewer than or equal to $10 \mathrm{ppm}$. Data from patients who returned for clinic visits and provided selfreport and $\mathrm{CO}$ measures were included in the analyses. A total of 1,046 paired measures were obtained from each of the four follow-up visits $(291,287,236$, and 232, at 4 and 9 weeks and at 6 and 12 months, respectively).

The agreement between self-report and expired CO was calculated using the Cohen's kappa statistic. Pearson's correlations were performed to determine the relationship between number of cigarettes per day and CO levels. Data were analyzed using the PASW statistical software program (Version 18.0) and the OpenEpi Epidemiologic Calculator.

\section{Results}

Patients were predominantly male (84\%) and the mean age was 54 years (standard deviation [SD] 10). Patients smoked an average of 33 years (SD 12) and 36\% reported having another smoker at home. On average, patients reported smoking 23 cigarettes per day (SD 11) and 63\% reported low-to-moderate nicotine dependence at baseline.

At 12 months, biochemical validation correlated with selfreported smoking status for 182 of 232 patients (kappa = $0.54 ; 95 \%$ confidence interval, $0.44-0.57$ ). This pattern was consistent across all follow-up visits (data not shown). Of the discordant pairs, two $(0.9 \%)$ included a self-report of nonsmoking but a positive CO reading. These patients had a mean CO level of $24.5 \mathrm{ppm}$ (SD 5.5). The remaining 48 discordant pairs included a self-report of smoking and a negative $\mathrm{CO}$ reading (false negatives, $n=48$ ). These patients had a mean CO level of $5.9 \mathrm{ppm}$ (SD 2.6) and reported smoking a median of 4 (interquartile range $1.4,8.5$ ) cigarettes per day. Patients with both a positive $\mathrm{CO}$ and self-report had an average $\mathrm{CO}$ of 18.7 (SD 7.7) and reported smoking a mean of 11.9 (SD 7.6) cigarettes per day.

At 12 months, the number of cigarettes smoked per day was positively correlated with expired CO levels $(r=0.70$, Figure 1). The strength of the correlation increased across the 12-month follow-up (data not shown). Among patients who reported smoking more than 14 cigarettes per day, 90\% had a CO reading greater than $10 \mathrm{ppm}$.

\section{Discussion}

Our study was designed to examine the validity of self-report for outpatient ascertainment of smoking status in post-MI patients. We found that biochemical validation by $\mathrm{CO}$ was only able to increase the likelihood of detecting smokers by less than $1 \%$ in patients. However, it may have discouraged patients from denying their smoking status and therefore should be considered for routine assessment of smoking 
status in the outpatient cardiac setting.

Self-report remains the conventional method for ascertaining smoking status in the outpatient post-MI setting. However, it has been found to be an inaccurate marker of smoking status. ${ }^{9}$ Moreover, biochemical validation has been shown to reduce the social desirability bias that often occurs in patients who suffer a major health event. ${ }^{9}$ A study investigating the validity of self-report found that patients with acute coronary syndrome (ACS) were more likely to deny their smoking status versus healthy individuals. ${ }^{11,12}$ Our finding that $\mathrm{CO}$ was only able to increase the likelihood of detecting smokers by less than $1 \%$ does not support these previous findings. However, knowledge of having to undergo biochemical validation may have deterred patients from denying their smoking status.

Our study had several limitations that should be noted. First, individuals who participated in the original study had to be motivated to quit smoking. This may explain the minimal effect of $\mathrm{CO}$ above that of self-report. Second, the knowledge of using a CO monitor at each clinic visit might have discouraged patients to deny their smoking status. Finally, we did not collect data on factors that could potentially affect the ability to detect biological levels of expired CO in the body (e.g., levels of physical activity, time since last cigarette, puffing habits). This could potentially explain the inability of CO to detect individuals who reported having returned to smoking.

\section{Conclusion}

Our study was designed to examine the validity of self-report for outpatient ascertainment of smoking status in post-MI patients. We found that expired CO does not substantially increase the likelihood of detecting smokers who would otherwise deny smoking. However, it may discourage patients from denying their smoking status and therefore should be considered for routine assessment of smoking status in the outpatient cardiac setting.

\section{References}

1. Antman EM, Hand M, Armstrong PW, et al. 2007 focused update of the ACC/AHA 2004 guidelines for the management of patients with ST-elevation myocardial infarction: a report of the American College of Cardiology/American Heart Association Task Force on Practice Guidelines. J Am Coll Cardiol 2008;51:210-47.

2. Jorenby DE, Hays JT, Rigotti NA, et al. Efficacy of varenicline, an alpha4beta2 nicotinic acetylcholine receptor partial agonist, vs placebo or sustained-release bupropion for smoking cessation: a randomized controlled trial. JAMA 2006;296:56-63.

3. Rigotti NA, Pipe AL, Benowitz NL, et al. Efficacy and safety of varenicline for smoking cessation in patients with cardiovascular disease: a randomized trial. Circulation 2010;121:221-9.

4. Rigotti NA, Thorndike AN, Regan S, et al. Bupropion for smokers hospitalized with acute cardiovascular disease. Am J Med 2006;119:1080-7.

5. Benowitz NL, Jacob P, Ahijevych K, et al. Biochemical verification of tobacco use and cessation. Nicotine Tob Res 2002;4,149-59.

6. Gariti P, Alterman AI, Ehrman R, et al. Detecting smoking following smoking cessation treatment. Drug Alcohol Depend 2002;65:191-6.

7. Gonzales D, Rennard SI, Nides M, et al. Varenicline, an alpha4beta2 nicotinic acetylcholine receptor partial agonist, vs sustained-release bupropion and placebo for smoking cessation: a randomized controlled trial. JAMA 2006;296:47-55.

8. Jorenby DE, Leischow SJ, Nides MA, et al. A controlled trial of sustainedrelease bupropion, a nicotine patch, or both for smoking cessation. N Engl J Med 1999;340:685-91.

9. Murray RP, Connett JE, Lauger GG, et al. Error in smoking measures: effects of intervention on relations of cotinine and carbon monoxide to selfreported smoking. The Lung Health Study Research Group. Am J Public Health 1993;83:1251-7.

10. Eisenberg MJ, Grandi SM, Gervais A, et al. Bupropion for smoking cessation in patients hospitalized with acute myocardial infarction: a randomized, placebo-controlled trial. J Am Coll Cardiol 2013;62:524-32.

11. Pell JP, Haw SJ, Cobbe SM, et al. Validity of self-reported smoking status: comparison of patients admitted to hospital with acute coronary syndrome and the general population. Nicotine Tob Res 2008;10:861-6.

12. Wilcox RG, Hughes J, Roland J. Verification of smoking history in patients after infarction using urinary nicotine and cotinine measurements. Br Med J 1979;2:1026-8. 